\title{
Dynamic Thiol-Disulphide Homeostasis in Patients with Multiple Sclerosis
}

\author{
Gonul Vural1 ${ }^{*}$, Sadiye Gumusyayla1, Hesna Bektas ${ }^{2}$, Orhan Deniz' ${ }^{1}$, Merve Ergin ${ }^{3}$, \\ Ozcan Erel $^{4}$ \\ ${ }^{1}$ Department of Neurology, School of Medicine, Yildirim Beyazıt University, Ankara, Turkey \\ ${ }^{2}$ Department of Neurology, Atatürk Training and Research Hospital, Ankara, Turkey \\ ${ }^{3}$ Department of Clinical Biochemistry, Atatürk Training and Research Hospital, Ankara, Turkey \\ ${ }^{4}$ Department of Clinical Biochemistry, School of Medicine, Yildirim Beyazıt University, Ankara, Turkey \\ Email: "gonulvrl@gmail.com
}

Received 30 March 2016; accepted 17 July 2016; published 20 July 2016

Copyright (C) 2016 by authors and Scientific Research Publishing Inc.

This work is licensed under the Creative Commons Attribution International License (CC BY).

http://creativecommons.org/licenses/by/4.0/

cc) (7)

Open Access

\begin{abstract}
Objective: The aim of this study was to evaluate thiol-disulphide homeostasis in patients with Multiple Sclerosis (MS) during attack and remission. Design and Methods: A total of 82 patients admitted to our clinic were divided into 2 groups according to whether they are having an attack or not. Peripheral blood samples were taken from all patients and their native thiol, disulphide and total thiol concentrations were measured by a newly developed automated method. In addition, their disulphide/native thiol, disulphide/total thiol and native thiol/total thiol ratios were calculated. Results: The average disulphide values, disulphide/native thiol and disulphide/total thiol ratios of the patients with MS who were having an attack were found to be significantly higher compared to those in remission $(p=0.001, p=0.001, p=0.001$, respectively). Conclusion: Our results have shown that thiol-disulphide balance was shifted to the oxidative area during the relapse. These homeostasis parameters, which can be easily measured by this newly developed method at low costs, may be important in terms of showing the disease activity and presenting the underlying mechanisms of the disease.
\end{abstract}

\section{Keywords}

Multiple Sclerosis, Relapse, Oxidative Stress, Thiol-Disulphide Homeostasis

\section{Introduction}

Multiple Sclerosis (MS) is a chronic inflammatory immune-mediated demyelinating disease of the central nervous system (CNS), affecting more than 2 million people worldwide. The disease affects the brain, spinal cord

\footnotetext{
*Corresponding author.
}

How to cite this paper: Vural, G., Gumusyayla, S., Bektas, H., Deniz, O., Ergin, M. and Erel, O. (2016) Dynamic ThiolDisulphide Homeostasis in Patients with Multiple Sclerosis. World Journal of Neuroscience, 6, 214-219.

http://dx.doi.org/10.4236/wjns.2016.63026 
and optic nerves in the CNS. Patients with MS exhibit variable clinical course. The majority has a relapsingremitting disease course characterized by intermittent neurological disturbance (episodes of acute worsening, relapse, attacks) followed by progressive accumulation of disability that affects social and occupational functioning. MS is the most common cause of non-traumatic disability in young adults [1] [2].

Although various pathophysiological mechanisms such as inflammation, oxidative damage, excitotoxicity, demyelination, remyelination and axonal damage are considered to be the underlying cause of multiple sclerosis, the exact etiopathogenesis of the disease is still unknown [3]. The increased number of evidence has shown that oxidative stress plays a key role in the development of the disease by contributing to the degeneration of oligodendroglia and destruction of the myelin. Inflammation causes oxidative stress and oxidative stress causes inflammation and results in demyelination [1]. Clinical signs and symptoms of MS are the reflection of the pathological processes including this inflammation and demyelination [4].

In MS patients, many previous studies have evaluated some oxidative stress markers including an individual pro-oxidants and antioxidant parameters [5]-[9]. Oxidative stress is characterized by imbalance between ROS (radical oxygen species) and anti-oxidants. Therefore thiol-disulphide homeostasis is very important. Because this makes possible to evaluate the redox imbalance. Up to the date, only one side of this double-sided thioldisulphide balance has been measured by the method developed by Elman and Lysko [10]. Both of variables can measured one by one or cumulatively with a novel automated method developed by Erel et al. [11]. In this way, oxidative status can be fully evaluated.

In this study, we have examined the changes in thiol-disulphide homeostasis of MS patients in remission and relapse.

\section{Materials and Methods}

\subsection{Study Design}

A total of 82 patients with MS admitted to our neurology department were included in our study after receiving written informed consent form from them. All of the patients were diagnosed with MS according to the revised McDonald criteria. Patients were divided into two groups according to whether there is a relapse of the disease. Patients were considered to be in the relapse phase in the presence of newly emerged neurological signs and symptoms lasted more than 24 hours and in the presence of lesion with contrast observed in the MRI. Patients were considered to be in the remission phase if they have no new neurological signs and symptoms at least 3 months after the last attack and no lesion with contrast observed in the MRI. Patients with active infectious, renal or liver disease, diabetes were excluded from study. None of the patients were smokers. The study was approved by the local ethics committee.

Following the 12-hour fasting period, blood samples were taken and centrifuged at $1500 \mathrm{~g}$ for 10 minutes. Serum samples were separated and stored at $-80^{\circ} \mathrm{C}$ until the analysis was performed. Serum thiol-disulphide homeostasis (thiol-disulphide homeostasis) was determined by a new automatic measurement method developed by Erel et al. In this method, firstly, only dynamic and reducible disulphide bonds (-S-S) were reduced to free functional thiol groups (-SH) by $\mathrm{NaBH}_{4}$. The remaining of unused reductant sodium borohydride $\left(\mathrm{NaBH}_{4}\right)$ was consumed and removed with formaldehyde. Then all thiol groups including both reduced thiols and native thiols were detected after reaction with DTNB [5, 5'-dithiobis-(2-nitrobenzoic) acid]. Native thiol (-SH) and total thiol (-SH+-S-S) concentrations were measured. Half of the difference between total and native thiols ensured the dynamic disulphide amount (-S-S). In addition -S-S-/-SH, -S-S-/(-SH+-S-S-) and -SH/(-SH+-S-S-) ratios were automatically calculated [11].

\subsection{Statistical Analyses}

SPSS 20 (IBM Corp. Released 2011. IBM SPSS Statistics for Windows, Version 20.0. Armonk, NY: IBM Corporation) statistics software was used to evaluate the data obtained. Descriptive analyses were presented using mean and \pm standard deviation (SD) for normally distributed variables. Intergroup comparisons of normally distributed numerical variables were performed using Student $\mathrm{T}$ test (for comparison between two groups). The significance levels of the tests was accepted as $\mathrm{p}<0.05$ and $\mathrm{p}<0.01$.

\section{Results}

Clinical characteristics of the patients in the phase of remission and relapse were summarized in Table 1. 
Table 1. Clinical characteristic of two groups.

\begin{tabular}{cccc}
\hline Characteristic & Patients in the phase of relapse $(\mathrm{n}=40)$ & Patients in the phase of remission $(\mathrm{n}=42)$ & $\mathrm{p}$ value \\
\hline Mean age & $34.05 \pm 9.84$ & $34.83 \pm 11.07$ & Not significant \\
Gender & & & Not significant \\
Male & $17(42.5 \%)$ & $29(69 \%)$ & Not significant \\
Female & $23(57.5 \%)$ & $2.26 \pm 2.04$ & \\
EDSS & $1.81 \pm 1.89$ &
\end{tabular}

Thiol-disulphide profiles of the patients in relapse and remission phases were compared. As it can be seen in Table 2, both mean disulphide values (-S-S) and disulphide/native thiol (-S-S-/-SH) and disulfide/total thiol $(-\mathrm{S}-\mathrm{S} / \mathrm{SH}+\mathrm{S}-\mathrm{S})$ ratios of the patients in the relapse phase were found to be significantly higher compared to other patients in the remission phase $(p=0.001, p=0.001, p=0.001)$.

\section{Discussion}

Oxidative damage play a key role in neurodegenerative diseases [12]. Oxygen is essential for life, but its metabolism leads to production of damaging oxygen radical products (radical oxygen species-ROS). Protective mechanisms against ROS have been also developed. The imbalance between ROS production and antioxidant mechanisms was defined as "oxidative stress" by Sies in 1985 [5] [13]. Oxidative stress occurs when excessive amount of ROS is produced or the capacity of antioxidants is reduced. Due to the high oxygen consumption, low amount of antioxidants, high content of polyunsaturated fatty acids sensitive to peroxidation, rich iron content that may catalyze the oxidative damage, the central nervous system is susceptible to oxidative damage [6] [7] [14]. Measurement of oxidant and antioxidant parameters in the plasma gives us information about oxidative status. Thiols are essential tamps of antioxidants [15].

Thiols contain functional sulfhydryl group (-SH) which is consist of hydrogen and sulfur atom bound to a carbon atom [16]. Plasma thiol pool consists of albumin, protein, cysteine, homocysteine, glutathione, $\gamma$-glutamylcysteine and cysteinylglycine [17]. When oxidative stress is increased, thiol groups of proteins get into oxidant reactions through oxidants and turn into disulphide bonds. Formed disulphide bonds can be reduced to thiol groups. In this way, dynamic thiol-disulphide homeostasis is maintained [18]. This balance has an important role in antioxidant defense, detoxification, apoptosis, signal transduction, regulation of enzymatic activity, transcription and intracellular signaling mechanisms [19] [20].

In earlier studies, increased levels of oxidative molecules [6] [19] and decreased [21] [22] or increased [23] levels of antioxidant molecules in patients with MS have been presented and the relationship between oxidative stress markers and both disability [19] and subtypes of the disease [7] has been investigated. However, to the best of our knowledge, a report related to the thiol-disulphide homeostasis in MS has not been published, so far. According to the in vitro studies, imbalance in thiol-disulphide results in proliferation or apoptosis at the cellular level [24] [25]. In fact, the thiol-disulphide homeostasis may be impaired in MS patients. To date, thiol-disulphide homeostasis could be measured unilaterally [10], but now the method developed by Erel made possible to measure the both variables. In this method, the classical Ellman reagent was modified by adding formaldehyde solution. In this way, sulfhydryl groups can be determined using modified Ellman reagent [11]. In the present study, we measured native thiol, total thiol, disulphide levels using this new method and calculated disulphide/ native thiol, disulphide/total thiol, native thiol/total thiol ratios in MS patients. We found that disulphide and disulphide/native thiol and disulphide/total thiol ratios were significantly higher during relapse than those in remission. The increase in the disulphide, disulphide/total thiol and disulphide/native thiol ratio show that the redox balance system shifted to side of disulphide band formation. This increased oxidant status is compatible to information that inflammation leading demyelination can lead to oxidative stress and vice versa [1].

MS pathophysiology is a dynamic process including damage and repair mechanisms. The interaction between damage and repair mechanisms determines the clinical course of the disease [26]. Relapses causing acute or subacute clinical dysfunction and peaking in days or weeks followed by partial or complete remission of symptoms and signs are characteristic to MS [4] [26] [27]. In the absence of fever or infection, the presence of new neurological signs and symptoms recently emerged or reappearance of completely or partially improved symptoms and signs, lasting at least 24 hours and then improving in approximately 1 month is considered as relapse 
Table 2. Thiol-disulphide profiles of MS patients in relapse and remission phases.

\begin{tabular}{|c|c|c|c|}
\hline Parameters & $\begin{array}{l}\text { MS patients in relapse } \\
\text { phase }(n=40)\end{array}$ & $\begin{array}{l}\text { MS patients in remission phase } \\
\qquad(\mathrm{n}=42)\end{array}$ & p-value* \\
\hline Native thiol $(-\mathrm{SH}) \mu \mathrm{mol} \cdot \mathrm{l}^{-1}$ & $459.70 \pm 74.98$ & $460.95 \pm 61.05$ & 0.934 \\
\hline Total thiol (-SH+-S-S) $\mu \mathrm{mol} \cdot \mathrm{l}^{-1}$ & $507.06 \pm 72.18$ & $495.51 \pm 59.94$ & 0.432 \\
\hline Dynamic disulphide $(-\mathrm{S}-\mathrm{S}) \mu \mathrm{mol} \cdot \mathrm{l}^{-1}$ & $23.68 \pm 7.86$ & $17.06 \pm 6.80$ & 0.001 \\
\hline -S-S-/-SH. \% & $0.053 \pm 0.023$ & $0.038 \pm 0.016$ & 0.001 \\
\hline -S-S-/(-SH+-S-S-), \% & $0.048 \pm 0.018$ & $0.035 \pm 0.015$ & 0.001 \\
\hline -SH/(-SH+-S-S-), \% & $0.904 \pm 0.036$ & $0.911 \pm 0.132$ & 0.756 \\
\hline
\end{tabular}

${ }^{*} \mathrm{p}$ value $<0.05$ considered significant. Results are given as mean $\pm \mathrm{SD}$.

(acute attack). Sometimes, the examination of patients cannot put out that the existing findings are whether attack or not. In this case, contrast-enhanced magnetic resonance imaging is performed. New T2 lesions that are newly observed in MRI and the presence of lesion with T1 contrast are considered as attack [27]. Although BOS examination is not very preferable since it is invasive, this examination performed in the first 30 days after having an attack presents the mild lymphocytic pleocytosis as well as increased leukocyte infiltration biomarkers (CXCL 13, MMP-9, CXCL10) and tissue damage markers (NF-L, MBP) [28]. In particular, the MBP is important to show disease activity [29]. Today, due to the increased role of MRG and its significance, BOS examination has become an auxiliary diagnostic method used for diagnosing diseases. Diagnosis of attack is based on medical history, physical examination and MRI. Our results show that thiol-disulfide redox balance system has shifted to the oxidative side during acute exacerbation of MS. This may be important in terms of showing the mechanisms underlying the disease and disease activity. Therefore, we believe that measuring disulphide, disulphide/total thiol and disulphide/native thiol ratio in MS patients on their admission could beneficial for clinical assessment. It can become one of the auxiliary tests used for diagnosis of relapse. On the other hand, the correction of thiol-disulphide imbalance by administering additional antioxidant medications may be benefical in managing treatment of the multiple sclerosis and the reduction of the frequency of relapses.

Some limitations of our study include the inclusion of relatively small number of patients who admitted to a single center and the lack of longitudinal follow-up the patients to determine whether alteration of homeostasis could be predictive value for relapse, disability, clinical course, response to treatment, disease subtypes.

Moreover, this is a first study evaluated serum thiol-disulphide homeostasis in multiple sclerosis. We believe that this study opens up new way for understanding of the underlying physiopathological mechanisms of MS, and for the identification of potential new therapeutic targets. However, further research is required.

\section{Conclusion}

The results of our study showed that oxidative stress plays a major role in MS, and thiol-disulfide balance has shifted to the disulphide band formation during acute exacerbation of MS. This newly developed test can be used as a novel oxidative stress marker in MS patients with clinical relapse. Moreover, it is a cost-efficient and easily accessible method.

\section{Acknowledgements}

None.

\section{Conflict of Interest}

All the authors declare that there is no conflict of interest.

\section{Funding}

This research received no grant from any funding agency in the public, commercial or not-for-profit sectors. 


\section{References}

[1] Ortiz, G.G., Pacheco-Moises, F.P., Bitzer-Quintero, O.K., Ramirez-Anguiano, A.C., Flores-Alvarado, L.J., RamirezRamirez, V., et al. (2013) Immunology and Oxidative Stress in MultipleSclerosis: Clinicaland Basic Approach. Clinical and Developmental Immunology, 2013, 1-14. http://dx.doi.org/10.1155/2013/708659

[2] Peterson, J.W. and Trapp, B.D. (2005) Neuropathobiology of Multiple Sclerosis. Neurologic Clinics, 23, 107-129. http://dx.doi.org/10.1016/j.ncl.2004.09.008

[3] Tully, M. and Shi, R. (2013) New İnsights in the Pathogenesis of Multiplesclerosis—Role of Acrolein in Neuronal and Myelindamage. International Journal of Molecular Sciences, 14, 20037-20047. http://dx.doi.org/10.3390/ijms141020037

[4] Francis, G.S., Duquette, P. and Antel, J.P. (1996) Inflammatory Demyelinating Diseases of the Central Nervous System. In: Bradley, W.G., Daroff, R.B., Fenickel, G.M. and Marsden, C.D., Eds. Neurology in Clinical Practice, 2nd Edition, Butterworth-Heinemann, Boston, 1307-1343.

[5] Gonsette, R.E. (2008) Neurodegeneration in Multiple Sclerosis: The Role of Oxidativestress and Excitotoxicity. Journal of the Neurological Sciences, 274, 48-53. http://dx.doi.org/10.1016/j.jns.2008.06.029

[6] Karlik, M., Valokovic, P., Hancinova, V., Krizova, L., Tothova, L. and Celec, P. (2015) Markers of Oxidativestress in Plasma and Saliva in Patients with Multiplesclerosis. Clinical Biochemistry, 48, 24-28. http://dx.doi.org/10.1016/j.clinbiochem.2014.09.023

[7] Miller, E., Walczak, A., Saluk, J., Ponczek, M.B. and Majsterek, I. (2012) Oxidative Modification of Patient’s Plasma Proteins and Its Role in Pathogenesis of Multiplesclerosis. Clinical Biochemistry, 45, 26-30. http://dx.doi.org/10.1016/j.clinbiochem.2011.09.021

[8] Tassed, I., Agüera, E., Sanchez-Lopez, F., Feijoo, M., Giraldo, A.I., Cruz, A.H., et al. (2012) Peripheral Oxidative Stress in Relapsing-Remitting Multiples Clerosis. Clinical Biochemistry, 45, 440-444. http://dx.doi.org/10.1016/j.clinbiochem.2012.01.023

[9] Oliveira, S.R., Kallaur, A.P., Simao, A.N.C., Morimoto, H.K., Lopes, J., Panis, C., et al. (2012) Oxidative Stress in Multiple Sclerosis Patients in Clinical Remission: Association with the Expanded Disability Status Scale. Journal of the Neurological Sciences, 321, 49-53. http://dx.doi.org/10.1016/j.jns.2012.07.045

[10] Elman, G. and Lysko, H. (1979) A Precise Method for the Determination of Plasma Sulfhydryl Groups. Analytical Biochemistry, 93, 98-102. http://dx.doi.org/10.1016/S0003-2697(79)80122-0

[11] Erel, O. and Neselioglu, S. (2014) A Novel and Automated Assay for Thiol/Disulphide Homeostasis. Clinical Biochemistry, 47, 326-332. http://dx.doi.org/10.1016/j.clinbiochem.2014.09.026

[12] Floyd, R.A. and Carney, J.M. (1992) Free Radical Damage to Protein and DNA: Mechanisms İnvolved and Relevant Observations on Brain Undergoing Oxidative Stress. Annals of Neurology, 32, 22-27.

[13] Sies, H. (1985) Oxidative Stress. AcademicPress, London.

[14] Lassman, H. and van Horssen, J. (2011) The Molecular Basis of Neurodegeneration in Multiple Sclerosis. FEBS Letters, 585, 3715-3723.

[15] Erel, O. (2004) A Novel Automated Direct Measurement Method for Total Antioxidant Capacity Using a New Generation, more Stable ABTS Radical Cation. Clinical Biochemistry, 37, 277-285. http://dx.doi.org/10.1016/j.clinbiochem.2003.11.015

[16] Sen, C.K. and Packer, L. (2000) Thiol Homeostasis and Supplements in Physical Exercise. The American Journal of Clinical Nutrition, 72, 653-669.

[17] Turell, L., Radi, R. and Alvarez, B. (2013) Thethiolpool in Humanplasma: The Central Contribution of Albumin to Redox Processes. Free Radical Biology \& Medicine, 65, 244-253. http://dx.doi.org/10.1016/j.freeradbiomed.2013.05.050

[18] Jones, D.P. and Liang, Y. (2009) Measuring the Poise of Thiol/Disulfidecouples in Vivo. Free Radical Biology \& Medicine, 47, 1329-1338. http://dx.doi.org/10.1016/j.freeradbiomed.2009.08.021

[19] Circu, M.L. and Aw, T.Y. (2010) Reactive Oxygens Pecies, Cellular Redox Systems, and Apoptosis. Free Radical Biology \& Medicine, 48, 749-762. http://dx.doi.org/10.1016/j.freeradbiomed.2009.12.022

[20] Biswas, S., Chida, A.S. and Rahman, I. (2006) Redox Modifications of Protein-Thiols: Emerging Roles in Cell Signaling. Biochemical Pharmacology, 71, 551-564. http://dx.doi.org/10.1016/j.bcp.2005.10.044

[21] Koch, M., Mostert, J., Arutjunyan, A., Stepanov, M., Teelken, A., et al. (2008) Peripheral Blood Leukocyte No Production and Oxidative Stress in Multiple Sclerosis. Multiple Sclerosis, 14, 159-165. http://dx.doi.org/10.1177/1352458507082075

[22] Kirlin, W.G., Cai, J., Thompson, S.A. and Diaz, D. (1999) Glutathione Redox Potential in Response to Differentiation and Enzyme İnducers. Free Radical Biology \& Medicine, 27, 1208-1218. 
http://dx.doi.org/10.1016/S0891-5849(99)00145-8

[23] Hadzovic-Dzuva, A., Lepara, O., Valjevac, A., Avdagic, N., Hasic, S. Kiseljakovic, E., et al. (2011) Serum Total Antioxidant Capacity in Patients with Multiple Sclerosis. Bosnian Journal of Basic Medical, 11, 33-36.

[24] Ortiz, G.G., Macias-Islas, M.A., Pacheco-Moises, F.P., Cruz-Ramos, J.A., Sustersik, S., et al. (2009) Oxidatives Tressis İncreased in Serum from Mexican Patients with Relapsing-Remitting Multiple Sclerosis. Disease Markers, 26, 35-39. http://dx.doi.org/10.1155/2009/325847

[25] Besler, H.T. and Comoglu, S. (2003) Lipoprotein Oxidation, Plasma Total Antioxidant Capacity and Homocysteine Level in Patients with Multiple Sclerosis. Nutritional Neuroscience, 6, 189-196. http://dx.doi.org/10.1080/1028415031000115945

[26] Stadelman, C. and Brück, W. (2008) Interplay between Mechanisms of Damage and Repair in Multiple Sclerosis. Journal of Neurology, 255, 12-18. http://dx.doi.org/10.1007/s00415-008-1003-7

[27] Turan, O.F. (2013) Multipl Skleroz: Klinik Özellikler ve Seyir. In: Karabudak R. and Güç, D., Eds., Temel ve Klinik Nöroimmünoloji, Ada Basın Yayın, Ankara, 223-228.

[28] Modvig, S., Degn, M., Horwitz, H., Cramer, S.P., Larsson, H.B., Wanscher, B., et al. (2013) Relationship between Cerebrospinal Fluid Biomarkers for İnflammation, Demyelination and Neurodegeneration in Acute Optic Neuritis. PLoS ONE, 8, e77163. http://dx.doi.org/10.1371/journal.pone.0077163

[29] Sellebjerg, F., Christiansen, M., Nielsen, P.M. and Frederiksen, J.L. (1998) Cerebrospinal Fluid Measures of Disease Activity in Patients with Multiple Sclerosis. Multiple Sclerosis, 4, 475-479. http://dx.doi.org/10.1177/135245859800400603

\section{Submit or recommend next manuscript to SCIRP and we will provide best service for you:}

Accepting pre-submission inquiries through Email, Facebook, LinkedIn, Twitter, etc. A wide selection of journals (inclusive of 9 subjects, more than 200 journals)

Providing 24-hour high-quality service

User-friendly online submission system

Fair and swift peer-review system

Efficient typesetting and proofreading procedure

Display of the result of downloads and visits, as well as the number of cited articles

Maximum dissemination of your research work

Submit your manuscript at: http://papersubmission.scirp.org/ 